\title{
Parmak Ucundaki Bakım: Mobil Uygulama ve Şizofreni Hastalarının Bakımında Kullanımı
}

\author{
Buse Çetinkaya๑, Esra Uslu๑
}

${ }^{1}$ Nuh Naci Yazgan Üniversitesi, Ruh Sağlığı ve Psikiyatri Hemşireliği, Kayseri, Türkiye

Eskişehir Osmangazi Üniversitesi, Ruh Sağlığı ve Psikiyatri Hemşireliği, Ekişehir, Türkiye

Buse Çetinkaya, Arş. Gör. Esra Uslu, Dr. Öğr. Üyesi

Bu çalışma I. Ulusal Dijital Hemşirelik Kongresinde Teşvik Ödülü almıştır.

İletişim:

Arş. Gör. Buse Çetinkaya

Nuh Naci Yazgan Üniversitesi, Kayseri, Türkiye Tel: +905531747096

E-Posta: busecetinkaya234@gmail.com

\section{ÖZET}

Mobil sağlık; sağlık alanında giyilebilir teknolojiler, mesaj servisleri ve mobil cihazlar gibi bilgi ve iletişim teknoIojilerinin kullanımını kapsar. Mobil sağlığın bir ayağı olan mobil cihazların kullanımındaki artış sağlık hizmetleri sunumunu etkilemiş ve bakımda etkili bir araç haline gelmiştir. Mobil cihazlarla birlikte gelişen mobil uygulamalar ise sağlığın farklı alanlarında kullanılır olmuştur. Bu alanlardan birisi de ruh sağlığıdır. Ruhsal problem yaşayan bireyler; kullanımının kolay olması, damgalamadan uzak bir ortam sunması, öz yönetim imkanı tanıması ve kolay erişilebilir olması gibi nedenlerle mobil uygulamaları tercih etmektedir. Mobil uygulamalar dünya üzerinde 21 milyondan fazla kişiyi etkileyen şizofreni hastaları için de etkili bir seçenektir. Bu hastaların sıkıkla bakım verenlerin desteğine ihtiyaç duyduğu ve hastalıklarının yönetimine etkin katılmayı istediği göz önünde bulundurulduğunda mobil uygulamalar karşımızsa bir fırsat olarak çıkmaktadır. Ancak literatür bu anlamda şizofreni hastalarının daha az ilgi gördüğünü, yapılan çalışma sayısııın da sınırlı olduğunu vurgulamaktadır. Bu noktada amacı mobil uygulamaları ve şizofreni hastalarının bakımına yansımalarını incelemek olan bu derlemenin literatüre katkı sağlayacağı düşünülmektedir. Bu kapsamda derlemede literatür bilgisi doğrultusunda mobil sağlık, mobil uygulamalar ve gelişimi, mobil uygulamaların güçlü ve zayıf yönleri, seçimi, değerlendirmesi, ruh sağlığı alanında kullanımı ve şizofreni hastalarının bakımına yansımalarından bahsedilecektir.

Anahtar sözcükler: Mobil uygulamalar, mobil sağlık, mobil telefon, şizofreni, psikiyatrik bakım

\section{CARE ON FINGERTIP: MOBILE APPLICATION AND USAGE IN CARE OF SCHIZOPHRENIA PATIENTS}

\section{ABSTRACT}

Mobile health includes the utilization of information and communication technologies such as wearable technologies, message services and mobile devices in the area of health. The increase in the utilization of mobile devices which are a part of mobile health has affected the delivery of healthcare services and made them an effective instrument in care. On the other hand, mobile applications developing in parallel with mobile devices have begun to be used in different areas of health. One of these areas is mental health. Individuals suffering from mental problems prefer mobile applications due to a number of reasons like their usability, accessibility, as well as offering an environment far from stigmatization and an opportunity for self-management. Mobile applications are also an effective option for patients with schizophrenia which affects more than 21 million people in the world. Considering that these patients often need the support of caregivers and want to participate in the management of their illness actively; mobile applications are encountered as an opportunity. However, the literature stresses that patients with schizophrenia are regarded less in this respect and there is a limited number of studies. At this point, it is believed that this compilation, which aims to analyze mobile applications and their impacts on the care of patients with schizophrenia, will contribute to the literature. In this context, the compilation will touch upon mobile health, mobile applications and their development, strong and weak aspects of mobile applications, choice and evaluation of mobile applications, use of mobile applications in the area of mental health and their impacts on the care of patients with schizophrenia according to the literature knowledge.

Keywords: Mobile applications, mobile health, mobile telephone, schizophrenia, psychiatric care
Gönderilme Tarihi : 12 Nisan 2019

Revizyon Tarihi : 22 Mayıs 2019

Kabul Tarihi

: 24 Mayıs 2019 
D ünyada 7,6 milyar kişi cep telefonu kullanırken dört milyar kişi de internet kullanıcısıdır. Bu rakamsal değerler Türkiye'de ise sırasıyla 76 milyon kişi mobil telefon, 60 milyon kişi aktif internet kullanıcısıdır (1). Amerika'da telefon sahibi her üç kişiden birinin telefonunu sağlıkla ilgili bilgilere erişmek için kullandığı bilinmektedir (2). Mobil cihazların kullanımının artışı sağlık hizmetleri sunumunu etkilemiştir (3). Hasta sayılarının artışına bağlı olarak yükselen maliyet, sınırlı personel sayısı, donanım problemleri mobil cihazların sağlık alanında kullanımını yaygınlaştırmış (4) ve bakıma yardımcı olmuştur ve bakımın kalitesini artırmış, hastaların iyileşmelerine katkı sağlamıştır (3-5). Bununla birlikte mobil cihazlar hastaların kendi sağlık durumlarını kontrol edebilmelerine imkân tanımış ve bağımsız yaşantı sürdürebilmelerinde yardımcı olmuştur (6).

Mobil sağlık alanındaki bu gelişmeler beraberinde mobil uygulamaların da gelişimini sağlamıştır (3). Geliştirilen bu mobil uygulamalar hasta merkezli bakımın sunulmasını sağlamıştır. (5). Mobil uygulamalar sağlık profesyonelleri tarafından tercih edilmekte ve hastalıkların yönetiminde bakım için fırsat sunmaktadır (7). Günümüzde astım, diyabet gibi hastalıkların yanında ruhsal hastalıkların yönetiminde de mobil uygulamalar tercih edilmektedir (8).

Ruh sağlığı alanında mobil sağlık teknolojilerine olan ilginin artmasında ve psikiyatrik belirtilerin izlenmesinde mobil uygulamaların kullanılmasına karşın bu alanda bilgi eksikliği vardır (9). Şizofreni hastalarının uygun eğitim ve fırsat verildiğinde mobil teknolojileri başarıyla kullanabileceği belirtilmişlerdir (10). Yapılan deneysel çalışmalarda da mobil uygulamaların şizofreni hastalarının bakımına katkı sağladığı görülmüştür (11-14). Ancak bu konuda yapılmış çalışma sayısının sınırlılığı vurgulanmaktadır (15). Literatür taraması sonucunda ülkemizde bu konuda yapılan bir çalışmaya rastlanmamıştır. Bu nedenle bu derlemenin mobil uygulamaların ve şizofreni hastalarının bakımındaki yerinin anlaşılması noktasında literatüre katkı sağlayacağı düşünülmektedir. Bu noktada derlemede mobil sağlık kavramından, mobil uygulamalardan ve gelişim serüveninden, mobil uygulamaların güçlü ve zayıf yönlerinden, mobil uygulamaların seçiminden, değerlendirilmesinden, ruh sağlığı alanında kullanımından ve şizofreni hastalarının bakımına yansımalarından bahsedilecektir.

\section{Mobil sağlık}

Bilişim sistemlerinde ve teknolojide yaşanan gelişmeler sağlık hizmetleri sunumunda ve klinik araştırmalarda küresel bir kavram olan mobil sağlık teknolojilerinin temelini oluşturmuștur (16). Dünya Sağlık Örgütü (DSÖ) mobil sağlığı, bilgi ve iletişim teknolojilerinin sağlıkla ilgili alanlarda kullanılması olarak tanımlamıştır. Ayrıca e-sağlık kavramının ayrılmaz bir parçası olarak görmüştür (17). Sağlık Bakanlığı'nın mobil sağlık tanımı ise "Akıllı telefon, tablet, bilgisayar ve diğer mobil iletişim araçlarının sağlık bilgisini iletmek ve sağlık hizmeti sunumunu desteklemek için kullanılması" şeklindedir (18). Mobil sağlık; sağlığın izlenmesi, geliştirilmesi, desteklenmesi için cep telefonlarının, giyilebilir teknolojilerin, mesaj servislerinin, kablosuz cihazların kullanımını ve telefon yazılımlarıyla oyun ve mobil uygulamaların geliştirilmesini kapsamaktadır (19).

Mobil sağlık uygulamaları, coğrafi açıdan sağlık hizmetlerine erişimi kısıtlı olan ve sağlık bakımında desteğe erişimde güçlük yaşayan kişiler için etkili bir araçtır (20). Ayrıca bireylere sağlığın desteklenmesi ve tedavisinde tam zamanlı, kolay erişilebilir hizmet sunmaktadır (21). Mobil sağlık uygulamaları sayesinde hastane öncesi ve sonrası dönemlerde hastanın izlenmesi, kişiselleştirilmiş bilgi alması, eğitim materyali sunma ve destek alması gibi fırsatlar ortaya çıkmıștır (22). Böylelikle mobil sağlık uygulamaları, kişiselleştirilmiş teknolojiler ile kanser, diyabet, sigara kullanımı, fiziksel aktivite ve ruhsal sağlık gibi çeşitli durumlarda hastaların kendi sağlıklarını yönetebilmesine olanak tanımıştır (23).

\section{Mobil uygulama ve gelişim serüveni}

Mobil sağlık uygulamalarının bir ayağı olan mobil uygulamalar akıllı telefonlar ya da mobil cihazlarda çalıştırılmak üzere tasarlanmış yazılımlardır ve dağıtım platformlarından (appstore, Google play vb.) indirilebilmektedir (24). Dağıtım platformlarındaki uygulamalar kullanıcı ihtiyaçlarına göre geliştirilmiş ve çeşitli kategorilere ayrılmıştır (25). Bu kategorilerden bazıları; iletişim (e-posta, sosyal ağ vb.) oyun (bulmaca, strateji vb.) verimlilik (takvim, hesap makinesi vb.) (25), fotoğraf düzenleyici, anlık mesajlaşma ve sağlık şeklindedir (26).

Mobil uygulamaların geçmişine bakıldığında ilk mobil uygulama1993 yılına telefona yüklenmiş olan takvim ve haritadır. Telefonlar uzun süre yalnızca bu iki özellikle donatılmışken 2002 yılında bir akıllı telefon markasının elektronik posta sistemini telefona entegre etmesi, telefona yüklenebilir uygulamaların başlangıcı sayılmıştır (27). Daha sonra akıllı telefon firmaları mobil uygulamaların hızlı bir şekilde yayılmasını sağlamış, kullanıcılar için farklı alanlarda uygulama sunumuna başlanmıştır (28). 
Mobil uygulamaların sunulduğu alanlardan biri de sağlıktır (29). Sağlık içerikli mobil uygulamalar on yılı aşkındır uygulama pazarında yer almaktadır (30). Sağlıkla ilgili her gün neredeyse 200 uygulamanın platformlara sunulduğu bildirilmiştir. Şu an ise sağlıkla ilgili 138 binden fazla mobil uygulama olduğu bilinmektedir (31). Her beş telefon sahibinden biri akıllı telefonuna sağlıkla ilgili mobil uygulama indirmektedir (32). Popüler uygulamaların indirilme oranına bakıldığında, oyunlardan sonra en çok tercih edilen uygulamaların arasında sağlık için kullanılan uygulamalar yer almaktadır (26). Indirilen uygulamaların içeriği ise kilo kontrolü, diyet, kan basıncı takibi gibi kişisel takip uygulamaları şeklinde sıralanabilir (32).

\section{Mobil uygulamaların güçlü yönleri}

Hasta açısından bakıldığında mobil uygulamalar ile kişiler kendi sağlık durumlarını yönetebilmektedir (33). Mobil sağlık uygulamaları ile kişiler kendilerine ait sağlık verilerini her an yanlarında taşıyabilir (34). Mobil uygulamalar damgalayıc olmayan ve günlük faaliyetlere iyi bir şekilde entegre olabilen, klinik açıdan da bakımın kalitesini artıran uygulamalardır (35). Ayrıca hastalara sağlıklı davranışları benimseme fırsatı sunar, sağlık hizmetlerini etkin kullanma becerisini artırır ve karar alma sürecinde özerklik sağlar. Bu durum hastaları güçlendirmektedir (36).

Sağlık profesyonelleri açısından değerlendirdiğimizde ise kişilerin kendilerine ait sağlık verilerini her an yanlarında taşıyabilmesi ve karşılıklı erişim imkânı sunması ile sağlık personeli ve hasta arasındaki iletişim güçlenmektedir (34). Ayrıca uygulamalar araştırma, değerlendirme, eğitim ve planlama sürecini kolaylaştırırken klinik karar vermeye katkı sağlarlar (37). Bununla birlikte hastalar, aileler ve bakım verenler için psikoeğitim aracı olarak kullanılabilir. Son olarak geri bildirimlerin kaydedildiği uygulamalar hastaların belirtilerinin kapsamlı değerlendirilmesini sağlar (38).

\section{Mobil uygulamaların zayıf yönleri}

Mobil telefonların sağlık hizmetlerine çabuk ve hızlı bir şekilde entegre olması birtakım sınırlılıkları da beraberinde getirmiştir (33). Geliştirilen uygulamalarda uygulamanın düzenli kullanılmaması halinde beklenen etki oluşmayabilir (39). Ayrıca telefonun pil ömrünün ve depolama alanının kısıtlı olması verimliliği azaltabilir (40). Bunun yanında uygulamayı geliştiren kişi her zaman bir klinik uzmanı olmayabilir (38). Bu durum uygulamaların güvenilirliğini tehlikeye sokar. Bazı uygulamaların sık sık güncellenmemesi de uygulamaların kısıtlı kaldığı yönlerindendir (38). Son olarak güvenlik ve mahremiyet, üzerinde önemle durulması gereken bir konudur (39). Uygulamalarda kişilerin özel bilgilerinin girilmesi, mahremiyet gerektiren bir konudur ve çoğunlukla kullanıcıyı anonim tutmak zordur. Bu nedenle uygulamalarda verilerin üçüncü kişilerle paylaşılması minimuma indirilmeli ve onam alınırken riskler hakkında kişiler bilgilendirilmelidir (41). Ayrıca verilerin saklanmasında telefon kullanılırken ve telefonun kayıp olması ihtimalinde verilerin de kaybolma ihtimali (42), mobil virüslerin neden olabileceği tehlike göz önünde bulundurulmalıdır (40).

\section{Mobil uygulamanın seçimi}

Dünya Sağlık Örgütü sağlık profesyonellerinin sağlık hizmetleri sunumunda teknolojik değişimlere uyum sağlaması ve fırsatları değerlendirmesi gerektiğini vurgulamaktadır (43). Bu noktada hemşireler bakımı şekillendirmek ve teknolojinin sağlıkta kullanımını artırmak, hastaları bakıma katabilmek ve hastaların kendi bakımlarının sorumluluğunu almalarını sağlamak için mobil uygulamaların potansiyelini ve sınırlarını bilmelidir (44). Çünkü hastalar mobil uygulamaların sayıca arttığı dönemde hangi uygulamayı seçeceklerine karar vermekte zorlanmakta (45) ve mobil uygulama seçiminde sosyal çevresinin yanı sıra sağlık profesyonellerinin önerisinden etkilenmektedir (46).

Uygulama seçimi yapılırken hastanın beklentileriyle orantılı bir uygulama tercih edilmelidir (45). Uygulamanın kullanımın kolay ve ucuz/ücretsiz olması kişiler tarafından tercih edilen bir özelliktir. Bu nedenle seçim sürecinde dikkat edilmesi gereken bir faktördür (46). Uygulama platformları kullanıcılara uygulamayı değerlendirme imkanı sunmaktadır. Uygulamanın geçmişteki değerlendirmelerinin yüksek memnuniyeti yansıtması uygulamayı seçilebilir kılmaktadır (47). Son olarak karar verirken uygulamanın yararları ile etik ilkelere uygunluğu karşılaştırılmalı ve uygulamanın yararları ön plana çıkarsa öneride bulunulmalıdır (46).

\section{Mobil uygulamanın değerlendirilmesi}

Hemşireler mobil uygulamaları önerirken mahremiyet, kişinin onayı, gizliliği, güvenliği ve zarar görme riski gibi konuları dikkatlice değerlendirmelidir (46). Ayrıca seçilen uygulamaların konu ile ilgili, güncel ve kanıta dayalı bilgiler içerdiğinden emin olmalıdır (48). Mobil uygulamaların değerlendirilmesinde Amerikan Psikiyatri Birliği hastalar ve klinisyenler için bir uygulama değerlendirme çerçevesi sunmuştur. Değerlendirme dört alanı kapsamaktadır. Mobil uygulama seçildikten sonra güvenlik ve mahremiyet, değerlendirilmesi gereken ilk alandır. Güvenliğin sağlanması ve kişisel bilgilerin saklanma koşullarına, uygulamanın gizlilik politikası olup olmadığına bakılmalıdır. 
Kanıt basamağına gelindiğinde uygulama kapsamı, içeriği ve etkinliği değerlendirilmelidir. Kullanım kolaylığı, değerlendirilmesi gereken üçüncü alandır. Ancak öznel bir durum olduğu için genel hatları ile uzun süreli kullanıma uygunluğuna, kişiselleştirilebilme özelliğine, aktif bağlantı intiyacına bakarak değerlendirilebilir. Birlikte çalışabilirlik ise değerlendirmenin son alanıdır. Uygulamanın verilerinin hangi alanda, kimlerle paylaşılabileceğine bakılarak değerlendirme süreci tamamlanır (49).

\section{Mobil uygulamaların ruh sağlığı alanında kullanımı}

Ruh sağlığı alanındaki mobil uygulamalar sayıca hızlı bir artış göstermiş aynı zamanda sağlık ekonomisini şekillendirmiştir (50). Akıllı telefonlarda yer alan mobil sağlık uygulamalarının \%29 unun ruh sağlığı üzerine tasarlandığı belirtilmiştir (51). Bu uygulamalar kullanıcılara eşit hizmet fırsatı sunmakta, her zaman ve her yerden erişim imkanı sağlamakta ve bireylerin kişisel becerilerini güçlendirmektedir (52). Aynı zamanda hastalık belirtilerinin izlemine ve yönetimine katkı sağlamaktadır (53).

Uygulamalar hastalara öz yönetim imkanının yanı sıra sağlık profesyonellerine tanı ve tedaviyi destekleme fırsatı da sunmaktadır (50). Hemşireler, mobil uygulamayı ruhsal hastalıkların önlenmesi ve tedavisinde kullanım için uygun, güvenilir ve kullanışlı bir kişisel yönetim aracı olarak görmektedir (54). Buna ek olarak mobil uygulamalar ile hastaların güçlenmesinin sağlandığını ve bakımın kalitesinin arttığını belirtmektedirler (55)

Mobil uygulamaların ruh sağlığı alanında kullanımı psikiyatrik rahatsızığı olan kişilerin de dikkatini çekmiştir (56) Psikiyatrik bir tanı alan hastalarının \%72'si mobil uygulamaları kullanmak için istekli olduklarını bildirmişlerdir (10). Psikotik bozukluğu olan kişilerin ise \%66 oranında mobil teknoloji kullandığı, bu sayının yıllar geçtikçe arttığı ve \%80'in üzerine çıktığı belirtilmektedir (9). Şizofreni hastaları da bu durumdan etkilenmiş, hastalar yaşam tarzlarını düzenlemek ve özyönetimlerini geliştirmek için uygulamaları kullanmada istekli olduklarını belirtmişlerdir (57). Makalenin bu bölümünde şizofreni hastalarının bakı$\mathrm{m}$ için geliştirilen mobil uygulamalara ilişkin çalışmalara yer verilecektir.

\section{Mobil uygulamaların şizofreni hastalarının bakımına yansımaları}

Şizofreni dünyada 21 milyondan fazla kişiyi etkileyen kronik bir hastalıktır (58). Şizofreni hastaları ilaçlarının yan etkileri, hastalık belirtileri ve (59) damgalama kaygıları (60) nedeniyle taburculuk sonrası dönemde günlük aktivitelerini yerine getirmekte sıklıkla bakım verenlerin desteğine intiyaç duymaktadır (61). Ancak hastalar bu süreçte kendilerini yalnız hissettiklerini ifade etmişlerdir. Bu nedenle her an ulaşabilecekleri nitelikte bir sağlık hizmetine ihtiyaç duymakta ve hastalığın yönetiminde aktif rol almak istemektedirler (62).

Hastalık yönetiminde ilaçlar etkili bir seçenek olarak karşımıza çıkmaktadır (58). Pozitif belirtilerin yönetiminde antipsikotik ilaçlar yarar sağlasa da bu hastalar bilișsel ve davranışsal belirtilerin yönetiminde bireysel uygulamalara ihtiyaç duymaktadır. (63). Bu kapsamda hastalara kendi sağlıklarını kontrol etme imkanı sunan, damgalamadan uzak bir ortam sağlayan (64) hastalıkların teşhisinde, takip ve tedavi edilmesinde kolay erişilebilen, bununla birlikte düşük maliyetli bakım sunan mobil uygulamalar karşımıza bir fırsat olarak çıkmaktadır (15).

Mobil uygulamaların şizofreni hastalarına sağladığı katkıya karşın örneklemini şizofreni hastalarının oluşturduğu çalışmalar nicel sınırlılık göstermektedir (15). Yapılan incelemeler sonucunda şizofreni hastalarının bakımında mobil uygulamaların kullanıldığı on adet çalışmaya ulaşılmıştır. Çalışmaların ikisi yarı deneysel, dördü nitel, ikisi randomize kontrollü, biri tanımlayıcı, biri ise protokol çalışmasıdır. Altı çalışmanın örneklemini yalnızca şizofreni hastaları oluştururken, üç çalışmada örnekleme diğer ruhsal bozukluğu olan bireyler de dâhil edilmiştir. Bu bölümde sınırlı sayıda çalışmanın ortaya koyduğu sonuçlar sunulacaktır.

İlk çalışma Palmier-Claus ve ark. (2012) tarafından yapılmıştır. Yarı deneysel desende tasarlanmış çalışmanın örneklemini 44 şizofreni hastası oluşturmuştur. Bu çalışmanın amacı psikotik belirtileri takip etmek için geliştirilen bir uygulamanın geçerliğini ve güvenirliğini belirlemek olmuştur. Bu amaç doğrultusunda "ClinTouch" isimli bir mobil uygulama geliştirilmiştir. Hastalardan gün içinde rastgele zamanlarda telefonlarına uyarı geldiğinde belirtilerini rapor etmeleri istenmiştir. Hastalar uygulamayı bir hafta süresince kullanmışlardır. Araştırmanın sonuçları ClinTouch uygulamasının belirti yönetimi ve hastanın klinik tablosunun takibi üzerinde etkili olduğunu ortaya koymuştur (12).

Konuyla ilgili nitel desende tasarlanan çalışma yine PalmierClaus ve ark. (2013) tarafından yapılmıştır. Çalışmanın örneklemini 24 şizofreni hastası oluşturmuştur. Çalışmanın amacı kısa mesaj uygulamasının ve mobil bir uygulamanın hastaların günlük yaşamlarında ve klinik bakımlarında 
hastalar tarafından nasıl algılandığını ve değerlendirildiğini ortaya koymaktır. Hastalar altı gün kısa mesaj uygulaması kullanmış bir hafta ara vermişler, sonrasında altı gün mobil bir uygulama kullanmışlardır. Uygulama ve kısa mesajın içeriği hastaların belirtilerini derecelendirmeye yöneliktir. Çalışma sonucunda hastalar mobil uygulamanın kısa mesaja göre daha düzenli ve kullanımının hızlı olduğunu belirtmişlerdir. Mobil uygulamaların klinik bakımda ve günlük yaşamda aktif kullanılabilir olduğu ve damgalamadan uzak bir ortam sunduğunu ifade etmişlerdir (35).

Konuyla ilgili bir diğer çalışma Ben-Zeev ve ark. (2013) tarafından yürütülmüştür. Bu çalışmanın ilk adımında geliştirilecek bir mobil uygulamaya dair beklentileri ortaya koymak amacıyla 904 şizofreni hastasına ulaşıımıştır. Hastaların beklentileri doğrultusunda uygulama içeriği; ilaç tedavisine uyum, duygu durum, uyku ve işitsel halüsinasyon yönetimi ile sosyal işlevselliği artırma şeklinde belirlenmiştir. Sonrasında "FOCUS" isimli mobil uygulama geliştirilmiştir (65). Ben-Zeev ve ark. (2014) araştırmanın ikinci aşamasında FOCUS mobil uygulamasının etkinliğini 33 şizofreni hastası ile test etmişlerdir. Çalışma ön test - son test deseninde tasarlanmış olup, hastalardan mobil uygulamanın bir ay boyunca kullanılması istenmiştir. Bu araştırmanın sonuçları uygulamanın hastalık belirtilerini azalttığını, hastalık yönetiminde uygulanabilir ve kabul edilebilir bir yöntem olduğunu ortaya koymuştur (11).

Ulaşılan diğer bir çalışma yine Palmier-Claus ve ark. (2014) tarafından yürütülmüştür. Bu çalışmalarında geliştirdikleri "ClinTouch" isimli uygulama kullanılarak psikotik belirti düzeyi ile kendine zarar verme davranışı arasındaki ilişkiyi incelemişlerdir. Çalışmaya 36 şizofreni hastası katılmıştır. Tanımlayıcı desende yapılan çalışmada hastalar bir hafta boyunca gün içinde hastalıklarına dair yaşadıkları belirtileri sisteme girmişler, bir hafta sonra veriler çalışmacıya gönderilmiştir. Sonuçlar belirtiler ve kendine zarar verme düşünceleri arasındaki ilişkiyi ortaya koymuştur (66). Bu çalışma aynı zamanda mobil uygulamaların verilerinin toplanması ve değerlendirmesinde kullanılabilir olduğunu göstermiştir.

Örnekleminde şizofreni hastalarına da yer verilen çalışmalardan biri Naslund ve ark. tarafından (2015) yapılmıştır. Nitel desende tasarlanan çalışmanın örneklemini ciddi ruhsal bozukluğu olan on hasta oluşturmuştur. Hastaların üçü şizofreni tanısı almıştır. Çalışmada "Peerfit" isimli kilo kontrol uygulaması kullanıımıştır. Çalışmanın amacı bu uygulamaya entegre edilmiş giyilebilir cihazların kullanılabilirliğini belirlemektir. Çalışma sonucunda giyilebilir ve uygulamaya entegre çalışan cihazların kilo kontrolünde yararlı olduğu görülmüştür. Ek olarak çalışma mobil uygulamanın sağlığın geliştirilmesinde kullanılabilir olduğunu göstermiştir (67).

Konu ile ilgili yapılan diğer nitel çalışma Macias ve ark. (2015) tarafından yürütülmüştür. Bu çalışma kapsamında "WellWave" isimli uygulamanın kabul edilebilirliğini ve kullanılabilirliğini test etmek amaçlanmıştır. Yapılan bu çalışmaya ruhsal bozukluğu olan on kişi dâhil edilmiş, bunlardan dördünü şizofreni tanılı hastalar oluşturmuştur. İlgili uygulama; kullanıcıların telefonlarına günlük olarak yapılacak faaliyetler, kendilerini değerlendiren formlar, ilaç hatırlatmaları gibi seçenekler sunmuştur. Uygulama, katılımcılar tarafından dört hafta kullanılmıştır. Çalışmanın sonucunda uygulamanın ruhsal bozukluğu olan bireylerde sağlığı geliştirmek için kabul edilebilir ve kolay erişilebilir olduğu gösterilmiştir (68).

Diğer bir çalışma Nicholson, Wright ve Carlisle tarafından (2018) yapılmıştır. Bu çalışma örnekleminde şizofreni tanısı olan bireyleri kapsayacak bir uygulamanın protokolünü içermektedir. Protokol hastalık yönetimi desteği sağlamak için oluşturulmuş WorkingWell uygulamasına aittir. Çalışmanın sonunda WorkingWell uygulamasının etkinliğinin deneme testinin gelecek çalışmalarda yapılacağı belirtilmiş̧ir (69).

Konuyla ilgili bir diğer çalışma Schlosser ve ark. tarafından (2018) yapılmıştır. Araştırmacılar bu çalışma kapsamında kişisel motivasyon geliştiren PRIME uygulamasını geliştirmişlerdir. Çalışmada PRIME uygulamasının sosyal işlevselliğin ve yaşam kalitesinin artırılmasındaki etkisini ve uygulamanın etkinliğini görmek amaçlanmıştır. Randomize kontrollü bu çalışma 43şizofreni hastası ile gerçekleştirilmiş olup, 22 kişi deney 21 kişi kontrol grubuna alınmıştır. Çalışma 12 hafta boyunca yürütülmüştür. Çalışmanın sonucunda uygulama, sosyal işlevselliği ve motivasyonu arttırmaya yönelik uygulanabilir, etkili bir müdahale olarak görülmüştür (14).

Diğer bir çalışma Terp, Jørgensen, Laursen, Mainz, \&Bjørnes (70) tarafından yürütülmüştür. Nitel desende tasarlanmış bu çalışmaya 13 şizofreni hastası katılmıştır. Çalışma kapsamında hastalara motivasyon sağlamak amacıyla "MindFrame" isimli bir mobil uygulama geliştirilmiştir. Araştırmanın temel amacını şizofreni hastalarının hastalıklarının yönetiminde bu uygulamayı nasıl kullandıklarını ve uygulamayı nasıl algıladıklarını ortaya koymaktır. Uygulama hastalar tarafından bir yıl boyunca kullanılmıştır. Sonuçlar, "MindFrame” uygulamasının düzenli 
kullanımda tedavide süreklilik sağladığını, hastalıkların takibinde ve kontrolünde bakımın bir parçası olduğunu göstermiştir (70).

Son çalışma Rojnic Kuzman ve ark. (2018) tarafından yürütülmüştür. Randomize kontrollü desende yapılan çalışmanın örneklemini şizofreni ve bipolar bozukluğa sahip hastalar oluşturmuştur. Örnekleme 78 hasta seçilmiş, bunlardan 36'sı deney grubu, 42'si kontrol grubu şeklinde ayrılmıştır. Çalışmanın amacı antipsikotik kullanımı kaynaklı yan etkilerin izlenmesi ve psikoeğitimin kolaylaştırılması için geliştirilen "PsyLOG" uygulamasının etkinliğini değerlendirmektir. Hastalar çalışma kapsamında dört ay boyunca ilaçlara bağlı oluşan yan etkilerini raporlamış ve 0-100 aralığında bir değerde puanlamışlardır. Çalışmanın sonucunda mobil uygulamanın standart psikiyatrik ölçeklere kıyasla yan etkileri bildirme konusunda daha etkili olduğu görülmüştür. Özellikle tedavinin erken dönemindeki hastalar için klinik yönetimde yararlı olacağı belirtilmiştir (13).

Özetle; değerlendirmeye alınan çalışmaların sonuçları şizofreni hastalarının bakımında kullanılan mobil uygulamaların hastaların belirti yönetimine katkı sağladığını, onları güçlendirdiğini ve damgalamadan uzak bir çevre sunduğunu ortaya koymuştur. Bununla birlikte uygulamaların hastanın klinik seyrinin takibine katkı sağladığını göstermiştir. Son olarak mobil uygulamalar hastalar tarafından kullanımı kolay ve erişilebilir bulunmuştur.

\section{Sonuç}

Uluslararası literatürde şizofreni hastalarının bakımında kullanılan mobil uygulamaların etkisinin incelendiği çalışmalar bulunurken, ülkemizde bu konuda yapılmış çalışmaya rastlanamamıştır. Bununla birlikte yapılan çalışmaların sayısının sınırlı, desenlerinin çoğunlukla nitel/tanımlayıcı olduğu, ancak kullanımının şizofreni hastaları üzerinde etkili olduğu görülmüştür. Son zamanlarda sağlık alanında kullanım sıklığı artan mobil uygulamaların hastaların bireysel desteğe ihtiyaç duyduğu noktada bakımı, klinik takibi ve hastalık yönetiminde, önemli bir potansiyele sahip olduğu düşünülmektedir. Bu bilgiler ışığında, özellikle ülkemizde mobil uygulamalar ile ilgili çalışmaların yapılması ve sonuçlarının değerlendirilmesi hastalık belirtilerinin yönetilmesine ve hemşirelik bakımına katkı sağlayacaktır.

\section{Kaynaklar}

1. Kemp S. Digital 2018: World's Internet Users Pass The 4 Billion Mark 2018 https://wearesocial.com/blog/2018/01/ global-digital-report-2018

2. Fox S, Duggan M. Mobile Health 2012. http://www.pewinternet. org/2012/11/08/mobile-health-2012/

3. Ventola CL. Mobile devices and apps for health care professionals: uses and benefits. P T 2014;39:356-64. https://www.ncbi.nlm.nih. gov/pmc/articles/PMC4029126/

4. Kaçmaz Ö. (Kitap Özeti) Mobil sağılı yeniliği: mobil öncüler için en iyi uygulamalar. Açıköğretim Uygulamaları ve Araştırmaları Derg 2015;1115-26. https://dergipark.org.tr/tr/download/ article-file/35555

5. Handel MJ. mHealth (Mobile Health) -Using Apps for Health and Wellness. Explore 2011;7:256-61. [CrossRef]

6. Arslan ET, Demir H. Üniversite Öğrencilerinin Mobil Sağlık ve Kişisel Sağlık Kaydı Yönetimine İlişkin Görüşleri. Aksaray Üniversitesi İktisadi ve İdari Bilimler Fakültesi Derg 2017;9:17-36. https://dergipark.org. tr/tr/download/article-file/415288

7. Elias BL, Fogger SA, McGuinness TM, D'Alessandro KR. Mobile apps for psychiatric nurses. J Psychosoc Nurs Ment Health Serv 2013;52:42-7. [CrossRef]

8. Firth J, Cotter J, Torous J, Bucci S, Firth JA, Yung AR. Mobile Phone Ownership and Endorsement of "mHealth" Among People With Psychosis: A Meta-analysis of Cross-sectional Studies. Schizophr Bull 2016;42:448-55. [CrossRef]

9. Torous J, Chan SR, Tan SYM, Behrens J, Mathew I, Conrad EJ, et al. Patient Smartphone Ownership and Interest in Mobile Apps to Monitor Symptoms of Mental Health Conditions: A Survey in Four Geographically Distinct Psychiatric Clinics. JMIR Mental Health 2014;1:e5. [CrossRef]

10. Ben-Zeev D. Mobile Technologies in the Study, Assessment, and Treatment of Schizophrenia. Schizophr Bull 2012;38:384-5. [CrossRef]

11. Ben-Zeev D, Brenner CJ, Begale M, Duffecy J, Mohr DC, Mueser KT. Feasibility, acceptability, and preliminary efficacy of a smartphone intervention for schizophrenia. Schizophr Bull 2014;40:1244-53. [CrossRef]

12. Palmier-Claus JE, Ainsworth J, Machin M, Barrowclough C, Dunn G, Barkus $\mathrm{E}$, et al. The feasibility and validity of ambulatory self-report of psychotic symptoms using a smartphone software application. BMC Psychiatry 2012;12:172. [CrossRef]

13. Rojnic Kuzman M, Andlauer O, Burmeister K, Dvoracek B, Lencer R, Koelkebeck K, et al. Effective assessment of psychotropic medication side effects using PsyLOG mobile application. Schizophr Res 2018;192:211-2. [CrossRef]

14. Schlosser DA, Campellone TR, Truong B, Etter K, Vergani S, Komaiko K, Vinogradov S. Efficacy of PRIME, a Mobile App Intervention Designed to Improve Motivation in Young People with Schizophrenia. Schizophr Bull 2018;44:1010-20. [CrossRef]

15. Firth J, Torous J. Smartphone Apps for Schizophrenia: A Systematic Review. JMIR mHealth and uHealth, 2015;3:e102. [CrossRef]

16. Steinhubl SR, Muse ED, Topol EJ. The emerging field of mobile health. Science Transl Med 2015;7:283rv3. [CrossRef]

17. WHO. mHealth Use of appropriate digital technologies for public health World Health Assembly-Seventy- First World Health Assembly 2018: http://apps.who.int/gb/ebwha/pdf_files/WHA71/A71_20-en. pdf

18. SağlıkBakanlığı. M-Sağlık (Mobil Sağlık) 2014. https://dijitalhastane. saglik.gov.tr/TR,4895/m-saglik-mobil-saglik.html

19. Kılıç T. e-Sağlık, İyi Uygulama Örneği; Hollanda. Gümüşhane Üniversitesi Sağlık Bilimleri Derg 2017;6:203-17. https://dergipark. org.tr/tr/download/article-file/386121 
20. Kovandžić M, Chew-Graham C, Reeve J, Edwards S, Peters S, Edge D, et al. Access to primary mental health care for hard-to-reach groups: from 'silent suffering' to 'making it work'. Soc Sci Med 2011;72:76372. [CrossRef]

21. Riley WT, Rivera DE, Atienza AA, Nilsen W, Allison SM, Mermelstein R. Health behavior models in the age of mobile interventions: are our theories up to the task? Transl Behav Med 2011;1:53-71. [CrossRef]

22. Zhao G, Wei D. Mobile health: new technologies, new modes and new era. J Biomed Res 2016;30:251-2. [CrossRef]

23. Parsons T. Consumer Electronics Can Help Improve Patient Health: Johns Hopkins Bloomberg School of Public Health; 2009. https:// www.jhsph.edu/news/news-releases/2009/gibbons-consumerhealth.html

24. Jahanshir A, Karimialavijeh E, Sheikh H, Vahedi M, Momeni M. Smartphones and Medical Applications in the Emergency Department Daily Practice. Emerg (Tehran) 2017;5:e14. https:// www.ncbi.n/m.nih.gov/pmc/articles/PMC5325882/

25. Islam R, Islam R, Mazumder TA. Mobile application and its global impact. IJET-IJENS 2010;10:72-8. https://citeseerx.ist.psu.edu/ viewdoc/download?doi=10.1.1.657.9773\&rep=rep1\&type=pdf

26. Özkoçak Y. Türkiye'de Akıllı Telefon Kullanıılarının Oyalanma Amaçlı Tercih Ettikleri Mobil Uygulamalar. Global Media J Turkish Ed 2016;6:106-30. https://www.guvenliweb.org.tr/dosya/b3m3V.pdf

27. Rajput M. Tracing the History and Evolution of Mobile Apps 2015. https://tech.co/news/mobile-app-history-evolution-2015-11

28. Charland A, Leroux B. Mobile application development: web vs. native. Communications ACM 2011;54:49-53. [CrossRef]

29. Güler E. Mobil sağlık hizmetlerinde oyunlaştırma. Açıköğretim Uygulamaları ve Araştırmaları Derg 2015;1:82-101. https:// dergipark.org.tr/tr/download/article-file/35562

30. Research2Guidance. mHealth App Economics 2017. https:// research2guidance.com/mhealth-app-developer-economics/

31. IQVIA. Impact of Digital Health Grows as Innovation, Evidence and Adoption of Mobile Health Apps Accelerate 2019: https://www.iqvia. com/en/newsroom/2017/11/impact-of-digital-health-grows-asinnovation-evidence-and-adoption-of-mobile-health-apps-accelerate

32. Fox S, Duggan M. Mobile health California HealthCare Foundation; 2012. http://marketing-farmaceutico.com/wp-content/ uploads/2012/11/PEW_MobileHealth2012.pdf

33. Patrick K, Griswold WG, Raab F, Intille SS. Health and the Mobile Phone. Am J Prev Med 2008;35:177-81. [CrossRef]

34. Güler E, Eby G. Akıllı Ekranlarda Mobil Sağlık Uygulamaları. Eğitim ve Öğretim Araştırmaları Derg 2015 4(3). http://www.jret.org/ FileUpload/ks281142/File/06.emel_guler.pdf

35. Palmier-Claus JE, Rogers A, Ainsworth J, Machin M, Barrowclough C, Laverty L, et al. Integrating mobile-phone based assessment for psychosis into people's everyday lives and clinical care: a qualitative study. BMC Psychiatry 2013;13:34. [CrossRef]

36. Guarneri R, Decandia Brocca M, Piras L. Patient's Empowerment and Behaviour Change: Complementary Approaches in EU Projects PALANTE and PEGASO. eHealth $360^{\circ}$ : International Summit on eHealth, Budapest, Hungary, June 14-16, 2016. p.359-69. [CrossRef]

37. Vezyridis P,Timmons S, Wharrad H. Going paperless at the emergency department: a socio-technical study of an information system for patient tracking. Int J Med Inform 2011;80:455-65. [CrossRef]

38. Zhang MWB, Ho CSH, Cheok CCS, Ho RCM. Smartphone apps in mental healthcare: the state of the art and potential developments. BJPsych Advances 2015;21:354-8. [CrossRef]

39. Kopmaz B, Arslanoğlu A. Mobil Sağlık ve Akıllı Sağlık Uygulamaları. Sağlık Akademisyenleri Derg 2018;5:251-5. [CrossRef]

40. Silva BM, Rodrigues JJ, Canelo F, Lopes IM, Lloret J. Towards a cooperative security system for mobile-health applications. IDEAS 2014:1-27. [CrossRef]
41. Carter A, Liddle J, Hall W, Chenery H. Mobile Phones in Research and Treatment: Ethical Guidelines and Future Directions. JMIR Mhealth Uhealth 2015;3:e95. [CrossRef]

42. Bakshi S. Advantages and disadvantages of mHealth 2018. http:// pharmabiz.com/PrintArticle.aspx?aid $=112537 \&$ sid=9

43. WHO. Health Employment and Economic Growth: World Health Organization; 2017: https://www.who.int/hrh/resources/WHO-HLCReport_web.pdf

44. Samples C, Ni Z, Shaw RJ. Nursing and mHealth. Int J Nurs Sci 2014;1:330-3. [CrossRef]

45. Lee J, Kim J. Informatics, Nursing. Method of app selection for healthcare providers based on consumer needs. Comput Inform Nurs 2018;36:45-54. [CrossRef]

46. East ML, Havard BC. Mental Health Mobile Apps: From Infusion to Diffusion in the Mental Health Social System. JMIR Ment Health 2015;2:e10. [CrossRef]

47. Huang H-Y, Bashir M. Users' Adoption of Mental Health Apps: Examining the Impact of Information Cues. JMIR mHealth and uHealth 2017;5:e83. [CrossRef]

48. Ferguson C, Jackson D. Selecting, appraising, recommending and using mobile applications (apps) in nursing. J Clin Nurs 2017. [CrossRef]

49. APA. App Evaluation Model. https://www.psychiatry.org/ psychiatrists/practice/mental-health-apps/app-evaluation-model

50. Marley J, Farooq S. Mobile telephone apps in mental health practice: uses, opportunities and challenges. BJPsych Bull 2015;39:288-90. [CrossRef]

51. Anthes E. Mental health:There's an app for that. Nature 2016;532:203. [CrossRef]

52. NIMH: National Institute of Mental Health. Technology and the Future of Mental Health Treatment; 2017. https://www.nimh.nih. gov/health/topics/technology-and-the-future-of-mental-healthtreatment/index.shtml

53. Wang K, Varma DS, Prosperi M. A systematic review of the effectiveness of mobile apps for monitoring and management of mental health symptoms or disorders. J Psychiatric Res 2018;107:738. [CrossRef]

54. Kaipainen K, Välkkynen P, Kilkku N. Applicability of acceptance and commitment therapy-based mobile app in depression nursing. Transl Behav Med 2016;7:242-53. [CrossRef]

55. Ngangue P, Gagnon M-P, Payne-Gagnon J, Desmartis M. m-Health adoption by healthcare professionals: a systematic review. J Am Med Inform Assoc 2015;23:212-20. [CrossRef]

56. Torous J, Wisniewski H, Liu G, Keshavan M. Mental Health Mobile Phone App Usage, Concerns, and Benefits Among Psychiatric Outpatients: Comparative Survey Study. JMIR Mental Health 2018:5:e11715. [CrossRef]

57. Lee K, Bejerano IL, Han M, Choi HS. Willingness to use smartphone apps for lifestyle management among patients with schizophrenia. Arch Psychiatr Nurs 2019;33:329-36. [CrossRef]

58. WHO. Schizophrenia; 2019. https://www.who.int/en/news-room/ fact-sheets/detail/schizophrenia

59. Velligan DI, Gonzalez JM. Rehabilitation and recovery in schizophrenia. Psychiatr Clin North Am 2007;30:535-48. [CrossRef]

60. Barbato A, WHO Nations for Mental Health Initiative \& World Health Organization. Division of Mental Health and Prevention of Substance Abuse. Schizophrenia and public health. Geneva; 1997. https://apps. who.int/iris/bitstream/handle/10665/63837/WHO_MSA_NAM_97.6 .pdf?sequence $=1$ \&isAllowed $=y$

61. Lin L-E, Lo S-C, Liu C-Y, Chen S-C, Wu W-C, Liu W-I. Effectiveness of Needs-oriented Hospital Discharge Planning for Caregivers of Patients with Schizophrenia. Arch Psychiatr Nurs 2018;32:180-7. [CrossRef] 
62. WHO. Schizophrenia Information for Families: Division of Mental Health World Health Organization 1992. https://apps.who.int/iris/ bitstream/handle/10665/61071/WHO_MNH_MND_92 8. pdf;jsessio nid=E225CB9F8B82D47E93E1726AACD780D9? sequence $=1$

63. Bauer M, Glenn T, Monteith S, Bauer R, Whybrow PC, Geddes J. Ethical perspectives on recommending digital technology for patients with mental illness. Int J Bipolar Disord 2017;5:6. [CrossRef]

64. Sandoval LR, Torous J, Keshavan MS. Smartphones for Smarter Care? Self-Management in Schizophrenia. Am J Psychiatry 2017;174:7258. [CrossRef]

65. Ben-Zeev D, Kaiser SM, Brenner CJ, Begale M, Duffecy J, Mohr DC. Development and usability testing of FOCUS. a smartphone system for self-management of schizophrenia. Psychiatric Rehabil J 2013;36:289-96. [CrossRef]

66. Palmier-Claus JE, Taylor PJ, Ainsworth J, Machin M, Dunn G, Lewis SW. The Temporal Association Between Self-Injurious Thoughts and Psychotic Symptoms: A Mobile Phone Assessment Study. Suicide Life Threat Behav 2014;44:101-10. [CrossRef]
67. Naslund JA, Aschbrenner KA, Barre LK, Bartels SJ. Feasibility of popular $\mathrm{m}$-health technologies for activity tracking among individuals with serious mental illness. Telemed J E Health 2015;21:213-6. [CrossRef]

68. Macias C, Panch T, Hicks YM, Scolnick JS, Weene DL, Ongur D, Cohen BM. Using Smartphone Apps to Promote Psychiatric and Physical Well-Being. Psychiatr Q 2015;86:505-19. [CrossRef]

69. Nicholson J, Wright SM, Carlisle AM. Pre-post, mixed-methods feasibility study of the WorkingWell mobile support tool for individuals with serious mental illness in the USA. a pilot study protocol. BMJ Open 2018;8:e019936. [CrossRef]

70. Terp M, Jørgensen R, Laursen BS, Mainz J, Bjørnes CD. A Smartphone App to Foster Power in the Everyday Management of Living with Schizophrenia: Qualitative Analysis of Young Adults' Perspectives. JMIR Ment Health 2018;5:e10157. [CrossRef] 